\title{
ESTIMASI PARAMETER MODEL GRAVITY DENGAN METODE INFERENSI-BAYES DAN FUNGSI HAMBATAN PANGKAT (STUDI KASUS KABUPATEN SUKOHARJO)
}

\author{
Nabila Astridayanti ${ }^{1}$, Syafi'i ${ }^{2)}$, Slamet Jauhari Legowo ${ }^{3)}$ \\ 1) Mahasiswa Fakultas Teknik, Prodi Teknik Sipil, Universitas Sebelas Maret \\ 2), 3) Pengajar Fakultas Teknik, Prodi Teknik Sipil, Universitas Sebelas Maret \\ Jl. Ir. Sutami No. 36A, Kentingan, Surakarta 57126; Telp. (0271) 647069, Fax 634524 \\ Email: nabilaastri@student.uns.ac.id
}

\begin{abstract}
The growing population will increase people's need for trip and can cause congestion therefore, it is necessary to have good transportation planning by using Origin-Destination matrix to estimate the trip distribution between locations. One of the ways to obtain O-D matrix is using Gravity model which contains $\beta$-parameter that must be known. Thus, the aims of this research were to estimate the value of this parameter, to determine the value of the trip distribution represented by O-D matrix and to determine the validity level of the modeling traffic flow compared to the observations. This research, conducted in Sukoharjo Regency, divided the area into 36 zones based on sub-district administrative boundaries. The O-D matrix estimation was determined using Production-Attraction Constrain Gravity model processed with EMME/3 software. The value of $\beta$-parameter was calibrated with Bayesian-Inference method and Power deterrence function by using MATLAB software. Traffic flows were obtained by assigning the $O-D$ matrix to the network then the test validity was done by using coefficient of determination $\left(\mathrm{R}^{2}\right)$. The results showed the value of $\beta$-parameter was 0,0771 with total trip distribution of 16374 pcu/ hour. The test validity showed the value of $\mathrm{R}^{2}$ was 0,8374 or categorized as very high level of validity.
\end{abstract}

Keywords: Bayesian-Inference, EMME/3, Gravity Model, O-D Matrix

\begin{abstract}
Abstrak
Pertumbuhan populasi penduduk yang terus bertambah akan meningkatkan kebutuhan pergerakan masyarakat dan dapat $m$ kemacetan lalu lintas untuk itu, perlu adanya perencanaan transportasi yang baik dalam suatu daerah, yaitu dengan menggunakan Matriks Asal-Tujuan (MAT) untuk memperkirakan distribusi pergerakan antar lokasi (zona). Salah satu cara dalam memperoleh MAT adalah dengan model Gravity yang mengandung parameter $\beta$ yang harus diketahui. Oleh karena itu, tujuan penelitian ini adalah untuk mengestimasi nilai parameter tersebut, mengetahui besar distribusi pergerakan yang diwakili dengan MAT dan mengetahui tingkat validitas arus lalu lintas hasil pemodelan yang dibandingkan dengan hasil pengamatan. Penelitian yang dilakukan di Kabupaten Sukoharjo ini membagi daerah kajian menjadi 36 zona berdasarkan batas administrasi kecamatan. Estimasi MAT diperoleh menggunakan model Gravity batasan bangkitan-tarikan yang diolah dengan perangkat lunak EMME/3. Nilai $\beta$ dikalibrasi dengan metode Inferensi-Bayes dan fungsi hambatan pangkat yang dibantu dengan perangkat lunak MATLAB. Arus lalu lintas diperoleh dengan membebankan MAT baru ke jaringan jalan yang kemudian dilakukan uji validitas menggunakan koefisien determinasi $\left(\mathrm{R}^{2}\right)$. Penelitian menghasilkan nilai parameter $\beta$ sebesar 0,0771 dengan total distribusi pergerakan sebesar $16.374 \mathrm{smp} / \mathrm{jam}$. Uji validitas menunjukkan nilai $\mathrm{R}^{2}$ sebesar 0,8374 atau tergolong dalam tingkat validitas sangat tinggi.
\end{abstract}

Kata Kunci : EMME/3, Inferensi-Bayes, MAT, Model Gravity

\section{PENDAHULUAN}

Indonesia adalah negara dengan pertumbuhan penduduk yang kian meningkat setiap tahunnya dan berpengaruh terhadap peningkatan kebutuhan pergerakan masyarakat. Kondisi ini akan berdampak pada masalah sistem transportasi darat apabila kebutuhan tersebut tidak diikuti dengan sarana dan prasarana yang memadai, salah satunya ialah kemacetan lalu lintas. Dalam jangka panjang, masalah ini dapat memengaruhi pembangunan negara sehingga harus segera diantisipasi. Oleh sebab itu, perlu dilakukan perencanaan transportasi yang baik yang mana dibutuhkan pemodelan untuk mencerminkan realita secara tepat. Bentuk pemodelan yang umum digunakan ialah model Perencanaan Empat Tahap (Four Step Model), salah satu tahapnya yakni distribusi pergerakan (trip distribution) yang berperan untuk memperkirakan pola pergerakan antar zona. Matriks pergerakan atau Matriks Asal-Tujuan (MAT) seringkali digunakan untuk menggambarkan pola pergerakan tersebut. Selain itu, pola pergerakan juga dapat dinyatakan dalam bentuk garis keinginan (desire line).

Salah satu metode yang umum digunakan untuk memperoleh MAT adalah model Gravity (GR). Untuk memperoleh MAT dalam penelitian ini digunakan model Gravity batasan bangkitan-tarikan. Parameter $\beta$ adalah salah satu parameter dalam model Gravity yang harus dicari karena mengindikasikan besarnya distribusi pergerakan dari 
zona asal $i$ ke zona tujuan (d). Oleh sebab itu, diperlukan penaksiran terhadap nilai parameter $\beta$ yang biasa disebut proses kalibrasi model. Nilai parameter $\beta$ menjadi tujuan penelitian ini yang mana dikalibrasi dengan menggunakan metode penaksiran Inferensi-Bayes dan fungsi hambatan pangkat. Selain itu, penelitian bertujuan untuk mengetahui besar distribusi pergerakan yang diwakili dengan MAT dan mengetahui tingkat validitas $\left(\mathrm{R}^{2}\right)$ arus lalu lintas hasil pemodelan yang dibandingkan dengan hasil pengamatan.

Dalam kurun waktu 5 tahun terakhir, Kabupaten Sukoharjo mengalami peningkatan angka pertumbuhan penduduk sebesar 2,27 persen, sementara itu jalan utama Kabupaten Sukoharjo juga menjadi jalur utama yang menghubungkan Kabupaten Wonogiri dengan Kota Surakarta. Berdasarkan kondisi tersebut, mendorong Kabupaten Sukoharjo menjadi kabupaten dengan pembangunan yang berkembang pesat. Akibatnya, masalah transportasi khususnya kemacetan lalu lintas, banyak terjadi di ruas jalan kabupaten ini, untuk itu perlu dilakukan studi kasus agar dapat mengetahui distribusi pergerakan estimasi MAT Kabupaten Sukoharjo sehingga diperoleh solusi untuk mengatasi permasalahan tersebut. Besar harapan agar penelitian ini dapat berguna bagi pengambil kebijakan sebagai acuan dalam perencanaan transportasi.

\section{DASAR TEORI}

\section{Perencanaan Transportasi}

Perencanaan transportasi pada hakikatnya merupakan suatu perencanaan kebutuhan prasarana dan sarana transportasi untuk mendukung sistem transportasi yang aman, efisien, dan berwawasan lingkungan. Perencanaan transportasi pada dasarnya bertujuan untuk memperkirakan jumlah dan lokasi kebutuhan akan transportasi (jumlah perjalanan, baik angkutan umum ataupun angkutan pribadi) pada masa yang akan datang (tahun rencana) untuk kepentingan kebijaksanaan investasi perencanaan transportasi.

\section{Matriks Asal-Tujuan (MAT)}

Matriks Asal-Tujuan (MAT) adalah informasi yang diperoleh dari salah satu empat tahapan perencanaan transportasi, yaitu distribusi pergerakan (trip distribution). MAT digambarkan sebagai matriks dua dimensi yang berisi informasi mengenai besarnya pergerakan antar lokasi (zona) di dalam suatu daerah.

\section{Model Gravity dan Metode Inferensi-Bayes}

Metode yang paling umum digunakan untuk memperoleh MAT adalah model Gravity (GR) dimana memiliki anggapan bahwa ciri bangkitan dan tarikan pergerakan erat kaitannya dengan beberapa parameter zona asal (zona $\imath$ ), seperti populasi, nilai sel MAT, dan aksesibilitas sebagai fungsi jarak, waktu, atau biaya. Dalam studi kasus ini digunakan model Gravity batasan bangkitan-tarikan sebagaimana persamaan [1] berikut.

$$
\text { Tid }=\text { Oi.Dd.Ai.Bd.f }(\mathrm{Cid}) \text {................................ [1] }
$$

Keterangan :

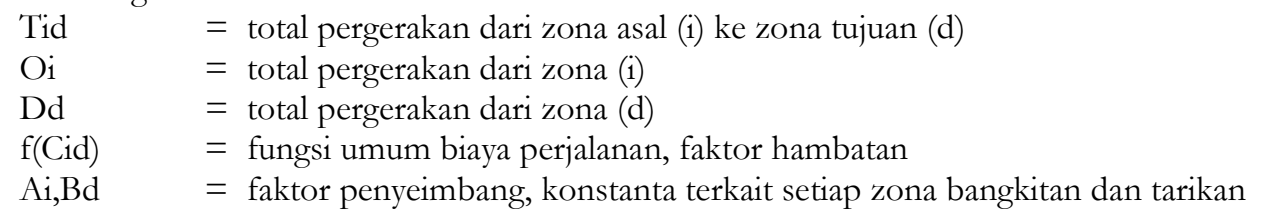

Fungsi hambatan yang dinyatakan dalam $\mathrm{f}(\mathrm{Cid})$ adalah anggapan sebagai ukuran aksesibilitas (kemudahan) antara zona i dengan zona d. Pada studi kasus ini digunakan fungsi hambatan pangkat sebagaimana persamaan [2] berikut. $f(\mathrm{Cid})=\mathrm{Cid}^{-\beta}$

Metode yang digunakan dalam kalibrasi parameter $\beta$ adalah metode Inferensi-Bayes (IB). Konsep metode IB adalah mengkalibrasi parameter sehingga selisih atau simpangan yang terjadi antara sebaran pergerakan dari data pengamatan (Tid) dengan yang dihitung dari model (Tid) dapat memberikan harga yang minimum. Persamaan metode IB dengan diketahui informasi awal dapat dinyatakan sebagai persamaan [3] berikut.

Memaksimumkan IB $($ iid Tid $)=$

$\sum_{i=1}^{N} \sum_{d=1}^{N}\left(T^{\prime} i d \log T i d\right)-0,5 \log _{e}$ Tid

Untuk mengetahui nilai maksimum, maka persamaan [4] harus sama dengan nol. 
$\frac{\partial I B(\text { idd } . T i d)}{\partial B}=f_{\beta}=\sum_{i=1}^{N} \sum_{d=1}^{N}\left(\frac{T^{\prime} i d}{\text { Tid }} \cdot \frac{\partial T i d}{\partial B}\right)-\left(\frac{0,5}{T i d} \cdot \frac{\partial T i d}{\partial B}\right)=0 \cdots . .[4]$

$\frac{\partial f}{\partial \beta}=\sum_{i=1}^{N} \sum_{d=1}^{N}\left[\left(\frac{\partial^{2} T i d}{\partial \beta^{2}}\right)\left(\frac{T^{\prime} i d}{\partial \beta^{2}}-\frac{0,5}{T i d}\right)+\left(\frac{\partial T i d}{\partial \beta}\right)\left(\frac{0,5}{T i d^{2}}-\frac{T^{\prime} i d}{T i d^{2}}\right)\right] \ldots[$ [5]

\section{Kalibrasi Newton-Raphson}

Kalibrasi adalah proses penaksiran nilai dengan melakukan pengulangan hingga nilai parameter mencapai batas konvergensinya dimana proses ini bertujuan untuk mengetahui nilai parameter $\beta$. Metode Newton-Raphson adalah metode dengan dasar pendekatan terhadap nilai $\mathrm{f}(\mathrm{x})$ menggunakan deret Taylor. Berikut persamaan yang digunakan.

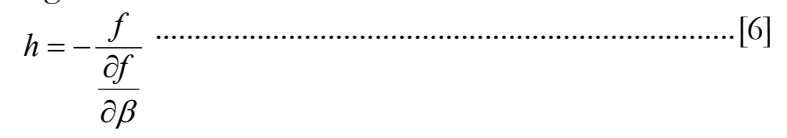

Persamaan [6] digunakan untuk mencari nilai h guna mendapatkan nilai pendekatan $\beta$ sebagai berikut.

$\beta_{1}=\beta_{0}+h$

Keterangan :

$\begin{array}{ll}\beta_{1} & =\text { nilai parameter } \beta \\ \beta_{0} & =\text { nilai asumsi parameter } \beta \text { atau } \beta \text { awal } \\ \mathrm{f} & =\text { fungsi } \mathrm{f} \text { terhadap parameter } \beta \\ \partial \mathrm{f} / \partial \beta & =\text { turunan dari fungsi } \mathrm{f} \text { terhadap parameter } \beta\end{array}$

\section{Indikator Uji Statistik}

Koefisien determinasi $\left(\mathrm{R}^{2}\right)$ menjadi indikator uji statistik yang digunakan dalam penelitian ini, dimana berguna untuk menguji validitas antara arus lalu lintas hasil pemodelan dengan hasil observasi. Hasil uji dengan nilai $\mathrm{R}^{2}$ yang mendekati nilai 1 (satu) mengartikan kemiripan yang tinggi antar arus lalu lintas yang diperbandingkan. Menurut Tamin (2000), indikator statistik R² memiliki model matematis seperti persamaan [8] berikut.

$$
R^{2}=\frac{\hat{\sum}\left(Y_{i}-\bar{Y}_{i}\right)^{2}}{\sum\left(Y_{i}-\bar{Y}_{i}\right)^{2}}
$$

Keterangan :

$\mathrm{R}^{2} \quad=$ koefisien determinasi

Yi = nilai $\mathrm{y}$ hasil pemodelan

$\hat{Y i}=$ nilai $\mathrm{y}$ hasil pengamatan

$\overline{\mathrm{Y}} \mathrm{i} \quad=$ rata-rata $\mathrm{y}$ hasil pengamatan

\section{METODE PENELITIAN}

\section{Lokasi dan Pengumpulan Data}

Penelitian ini dilaksanakan di Kabupaten Sukoharjo, Jawa Tengah. Kabupaten Sukoharjo secara administrasi terbagi menjadi 12 kecamatan dan terdiri dari 17 kelurahan serta 150 desa. Batas administrasi kecamatan menjadi dasar dalam pembagian zona penelitian ini, yang terdiri dari Kecamatan Kartasura, Gatak, Baki, Grogol, Mojolaban, Sukoharjo, Bendosari, Bulu, Ngunter, Polokarto, Tawangsari, dan Weru. Ruas jalan yang digunakan dalam survei adalah jalan kolektor dan arteri.

Data primer berupa data traffic count didapat dari survei penelitian pada jam puncak pagi hari yakni pukul 07.0008.00 dengan interval 15 menit di beberapa ruas jalan yang dianggap dapat mewakili jaringan jalan di wilayah kajian. Jumlah titik yang disurvei sebanyak 31 titik dengan 19 titik berada dalam wilayah kajian dan 12 titik menuju zona eksternal. Selain traffic count, dilakukan juga pengamatan terhadap hambatan samping pada ruas jalan yang diteliti. Data sekunder diperoleh dari beberapa instansi terkait Kabupaten Sukoharjo, seperti Badan Perencana Pembangunan Daerah (BAPPEDA), Dinas Perhubungan (Dishub), dan Dinas Pekerjaan Umum dan Penataan Ruang (DPUPR) Kabupaten Sukoharjo. 


\section{Pengolahan Data}

Hasil survei berupa traffic count kemudian dikonversikan ke dalam satuan mobil penumpang berdasarkan ketentuan MKJI 1997. Pengolahan data juga dilakukan dengan menghitung waktu tempuh dan kapasitas jalan berdasarkan lebar bahu jalan, lebar jalan, tipe jalan, jarak kereb (penghalang), hambatan samping, dan jumlah penduduk sesuai ketentuan MKJI 1997. Data koordinat juga dihitung berdasarkan posisi node dan centroid yang telah ditetapkan. Datadata tersebut akan menjadi data masukan pada perangkat lunak EMME/3.

\section{Estimasi Matriks Asal-Tujuan Hasil EMME/3}

Data yang telah diolah selanjutnya dimasukkan ke dalam perangkat lunak EMME/3 sebagai basis data jaringan jalan. Selain itu, dibutuhkan matriks awal (prior matrix) untuk menghasilkan matriks hasil estimasi yang mana dalam studi kasus ini tidak terdapat prior matrix yang berasal dari penelitian sebelumnya atau referensi lainnya terhadap MAT Kabupaten Sukoharjo sehingga data matriks awal diperoleh dengan memasukkan angka 1 ke dalam setiap sel matriks awal tersebut. Setelah menjalankan program EMME/3 dengan memasukkan data yang telah diolah, maka akan diperoleh hasil estimasi MAT.

\section{Kalibrasi Parameter $\beta$}

Proses kalibrasi dengan metode Newton-Raphson dilakukan hingga nilai $\beta$ mencapai batas konvergennya. Estimasi parameter $\beta$ dalam penelitian ini menggunakan fungsi hambatan pangkat dan metode estimasi Inferensi-Bayes yang dibantu dengan program MATLAB.

\section{Estimasi Matriks Asal-Tujuan Hasil Model Gravity}

Nilai $\beta$ yang diperoleh dari proses kalibrasi berguna untuk dapat menentukan estimasi MAT tahun 2021 dengan model Gravity batasan bangkitan-tarikan. Hasil yang diperoleh menggambarkan distribusi pergerakan hasil pemodelan dari suatu zona.

\section{Pembebanan Lalu Lintas}

Matriks baru hasil model Gravity yang telah diperoleh selanjutnya dibebankan ke jaringan jalan Kabupaten Sukoharjo dengan bantuan program EMME/3. Pembebanan dalam penelitian ini menggunakan metode User Equilibrium dengan pendekatan algoritme Frank Wolfe. Proses ini menghasilkan arus lalu lintas hasil pemodelan di setiap ruas jalan Kabupaten Sukoharjo.

\section{Uji Validitas}

Uji validitas berfungsi untuk mengetahui sejauh mana ketepatan model yang digunakan dalam studi kasus ini. Koefisien determinasi $\left(\mathrm{R}^{2}\right)$ menjadi indikator uji statistik dalam uji validitas ini. Tahap ini dilakukan dengan melakukan perbandingan antara arus lalu lintas hasil pemodelan yang diperoleh dari tahapan pembebanan lalu lintas (trip assignment) dengan arus lalu lintas hasil pengamatan yang diperoleh dari survei traffic count.

\section{HASIL DAN PEMBAHASAN}

\section{Nilai $\beta$ sebagai Parameter Fungsi Hambatan}

Kalibrasi Newton-Raphson dilakukan dengan bantuan software MATLAB sebagaimana hasil ditunjukkan pada Gambar 1.

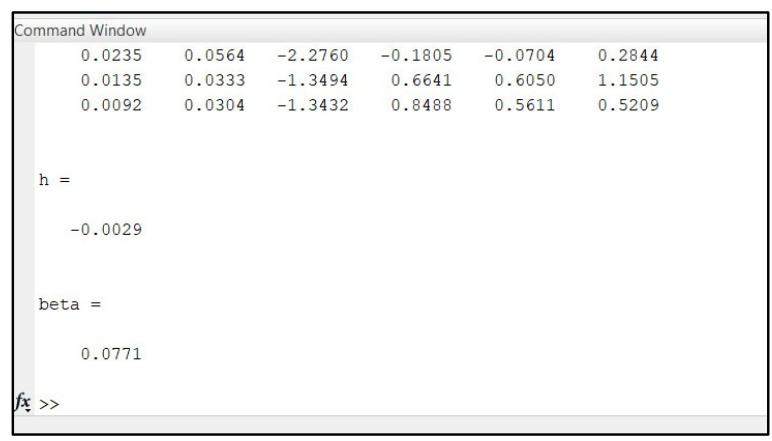

Gambar 1. Hasil kalibrasi parameter $\beta$ 
Gambar 1 tersebut menunjukkan hasil nilai parameter $\beta$ model Gravity sebesar 0,0771 yang mana diperoleh dengan menggunakan metode Inferensi-Bayes dan fungsi hambatan pangkat. Parameter $\beta$ didapat dengan mengasumsikan nilai $\beta$ awal $\left(\beta_{0}\right)$ sebesar 0,08 yang mana setelah proses kalibrasi didapat juga nilai h sebesar (-) 0,0029 .

\section{Distribusi Pergerakan Estimasi Matriks Asal-Tujuan}

Estimasi MAT hasil pemodelan dengan Model Gravity batasan bangkitan-tarikan menghasilkan distribusi pergerakan terhadap Kabupaten Sukoharjo tahun 2021 sebesar $16.374 \mathrm{smp} / \mathrm{jam}$. Distribusi pergerakan setiap zona dapat dilihat baik dalam bentuk matriks maupun bentuk desire line atau garis keinginan sebagaimana bentuk desire line ditunjukkan pada Gambar 2 berikut.

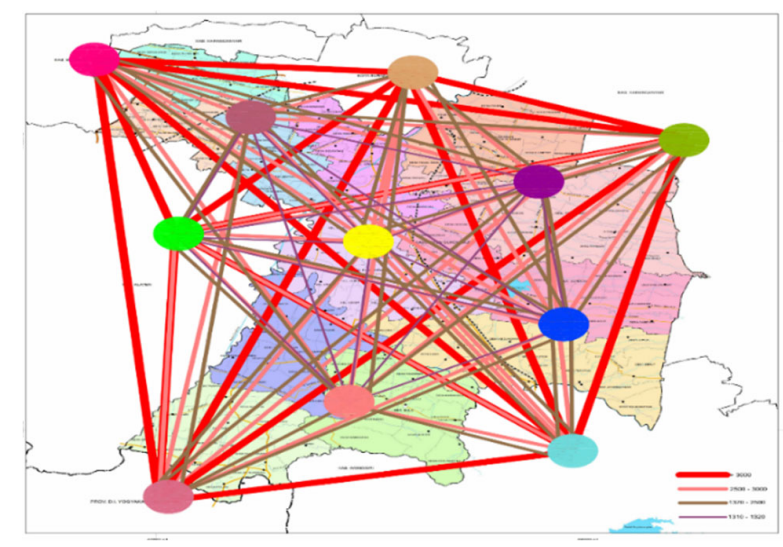

Gambar 2. Garis Keinginan (Desire Line) distribusi pergerakan lalu lintas Kabupaten Sukoharjo Tahun 2021

Titik yang terdapat pada Gambar 2 adalah titik yang mewakili pergerakan eksternal dan internal, dimana terdapat 5 titik yang mewakili pergerakan zona internal dan 6 titik yang mewakili pergerakan zona eksternal. Pergerakan Kabupaten Sukoharjo Tahun 2021 dapat diamati berdasarkan pergerakan yang terjadi antara masing-masing dari zona internal dan eksternal, yakni dengan membandingkan jumlah pergerakan baik antar zona internal-internal, zona eksternal-internal, zona internal-eksternal, maupun zona eksternal-eksternal seperti pada Gambar 3 berikut.

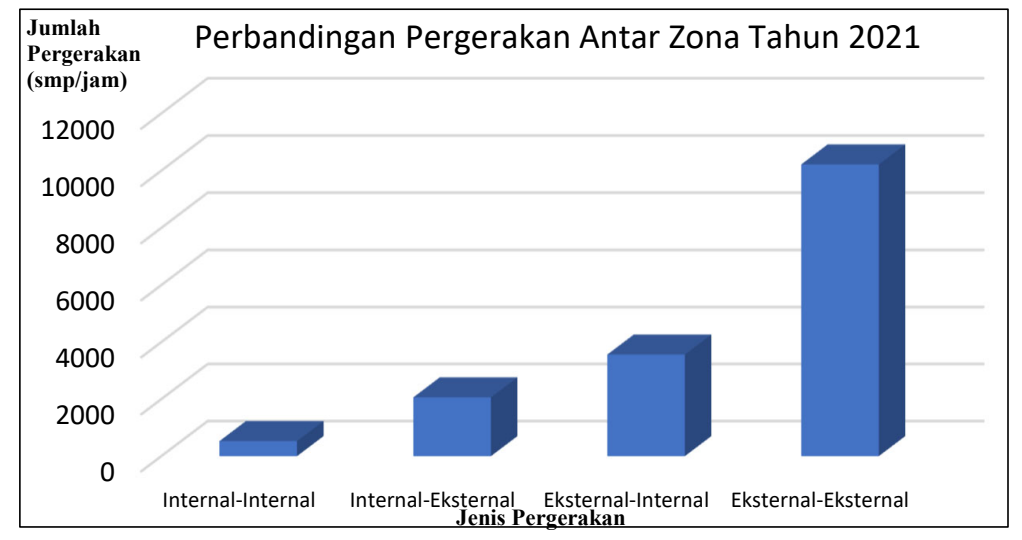

Gambar 3. Grafik perbandingan pergerakan antar zona Tahun 2021

Gambar 3 menggambarkan secara jelas bagaimana karakteristik pergerakan lalu lintas yang terjadi di Kabupaten Sukoharjo khususnya pada tahun 2021. Besarnya pergerakan antar zona dalam satuan smp/jam dan dalam persentase ditampilkan pada Tabel 1 berikut. 
Tabel 1. Perbandingan pergerakan antar zona

\begin{tabular}{lll}
\hline Jenis Pergerakan & Jumlah Pergerakan (smp/jam) & Persentase (\%) \\
\hline Eksternal-Eksternal & 10218 & 62,40 \\
Eksternal-Internal & 3563 & 21,76 \\
Internal- Eksternal & 2064 & 12,61 \\
Internal-Internal & 529 & 3,23 \\
\hline Total & 16374 & 100 \\
\hline
\end{tabular}

Berdasarkan Tabel 1, pergerakan antar zona eksternal-eksternal menunjukkan jumlah yang paling besar, Hal ini dapat terjadi akibat beberapa kemungkinan, antara lain faktor pertumbuhan penduduk dan faktor ketersediaan fasilitas. Lokasi Kabupaten Sukoharjo berbatasan langsung dengan kabupaten/kota yang berkembang dimana memiliki laju pertumbuhan penduduk yang meningkat setiap tahunnya. Kondisi ini berdampak pada pergerakan yang semakin meningkat pula dan menyebabkan tingginya pergerakan kendaraan yang berasal dari luar Sukoharjo melewati wilayah tersebut untuk menuju luar Sukoharjo juga. Selain itu, Kabupaten Sukoharjo bersebelahan langsung dengan Kota Surakarta, yang menjadi pusat kegiatan ekonomi di kawasan Subosukawonosraten. Tidak hanya kegiatan ekonomi, Kota Surakarta juga menyediakan fasilitas kesehatan dan pendidikan. Hal ini tentunya mendorong pergerakan masyarakat luar kota untuk melewati ruas jalan Kabupaten Sukoharjo menuju Kota Surakarta.

Sebaliknya pergerakan yang paling rendah ditunjukkan oleh pergerakan zona internal-internal dengan kemungkinan seperti tingkat pertumbuhan ekonomi Kabupaten Sukoharjo yang relatif rendah dibanding wilayah sekitarnya. Hal ini menyebabkan banyaknya masyarakat Sukoharjo yang melakukan pergerakan ke luar wilayah dengan tingkat pertumbuhan ekonomi yang lebih tinggi. Selain itu, dapat dipicu oleh jumlah penduduk usia kerja Kabupaten Sukoharjo yang relatif rendah dibanding wilayah sekitarnya. Hal ini tentunya memengaruhi pergerakan karena penduduk usia kerja akan banyak melakukan pergerakan ke luar untuk bekerja

\section{Uji Validitas}

Nilai $\mathrm{R}^{2}$ yang diperoleh dari hasil uji validitas terhadap perbandingan arus lalu lintas hasil pemodelan dengan hasil pengamatan adalah sebesar 0,8326 . Artinya nilai $\mathrm{R}^{2}$ dari penelitian ini menunjukkan hasil yang sangat tinggi. Hal ini dapat dilihat pada syarat rentang koefisien determinasi $\mathrm{R}^{2}$. Dengan nilai yang diperoleh dengan bantuan perangkat lunak EMME/3 tersebut, dapat diketahui juga bahwa terjadi galat sebesar 0,1674 atau 16,74\%.

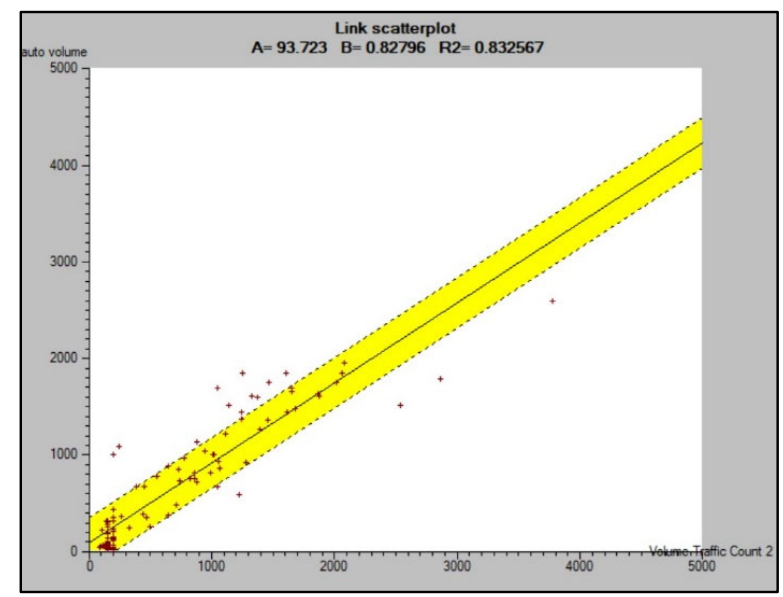

Gambar 4. Grafik uji validitas dari perbandingan arus lalu lintas hasil pemodelan dan hasil pengamatan

Berdasarkan Gambar 4 tersebut, nilai $\mathrm{R}^{2}$ yang diperoleh dari grafik tersebut juga mengindikasikan tingkat kemiripan yang sangat tinggi antara arus lalu lintas hasil pengamatan dan arus lalu lintas hasil pemodelan, yakni sebesar 83,26\% atau dalam kata lain, tidak terjadi penyimpangan antara kedua data arus lalu lintas yang dibandingkan. 
Jurnal Matriks Teknik Sipil

DOI: https://dx.doi.org/10.20961/mateksi.v9i1.52315

ISSN: 2354-8630

E-ISSN: 2723-4223

Vol 9, No 1 (2021): Maret

\section{SIMPULAN}

Berdasarkan studi kasus yang telah dilakukan terhadap Kabupaten Sukoharjo, maka dapat disimpulkan bahwa,

1. Nilai parameter $\beta$ yang merupakan fungsi hambatan pangkat dengan metode Inferensi-Bayes dan didapat dengan bantuan perangkat lunak MATLAB menghasilkan nilai sebesar 0,0771 .

2. Estimasi distribusi pergerakan Kabupaten Sukoharjo dengan model Gravity batasan bangkitan-tarikan menghasilkan total distribusi pergerakan pada tahun 2021 sebesar $16374 \mathrm{smp} / j a \mathrm{~m}$. Pola pergerakan antar zona memiliki masing-masing jumlah yakni sebagai berikut :
a. Eksternal-Eksternal
: $10218 \mathrm{smp} / \mathrm{jam} \quad(62,40 \%)$
b. Eksternal-Internal
: $3563 \mathrm{smp} / \mathrm{jam} \quad(21,76 \%)$
c. Internal-Eksternal
$: 2064 \mathrm{smp} / \mathrm{jam} \quad(12,61 \%)$
d. Internal-Internal
: $529 \mathrm{smp} / \mathrm{jam}$
$(3,23 \%)$

3. Hasil uji validitas dengan menggunakan koefisien determinasi diperoleh nilai $\mathrm{R}^{2}$ sebesar 0,8326 . Nilai $\mathrm{R}^{2}$ tersebut tergolong ke dalam rentang validitas sangat tinggi.

\section{REKOMENDASI}

Rekomendasi yang dapat diberikan pada penelitian berikutnya mengenai estimasi Matriks Asal-Tujuan Kabupaten Sukoharjo adalah sebagai berikut:

1. Memperbanyak jumlah titik yang disurvei agar perolehan data semakin banyak sehingga menghasilkan data yang lebih akurat terhadap pergerakan lalu lintas Kabupaten Sukoharjo.

2. Membarui data-data yang mendukung penelitian ini, terutama data jaringan jalan dari Dinas Pekerjaan Umum dan Penataan Ruang (DPUPR) Kabupaten Sukoharjo sehingga memperoleh data yang lebih sesuai dengan kondisi realitanya.

\section{UCAPAN TERIMAKASIH}

Terima kasih penulis tujukan kepada Bapak Dr. Eng. Ir. Syafi'i, M.T. dan Bapak Slamet Jauhari Legowo, S.T., M.T. selaku dosen pembimbing yang sudah bersedia membimbing penulis dalam penelitian ini. Terima kasih penulis ucapkan juga kepada kedua orang tua, saudari, dan rekan penulis yang telah memberi dukungan hingga selesainya tugas akhir ini.

\section{REFERENSI}

Dananto, Atha Fauzan Kito., 2019, "Studi Peramalan Kinerja Jaringan Jalan di Kota Surakarta pada Tahun 2035 Dengan Jaringan Jalan Tetap dan Dengan Penambahan Jaringan Jalan Baru", Fakultas Teknik Program Studi Teknik Sipil Universitas Sebelas Maret. Surakarta

Septiyani, Wulan., 2015, "Estimasi MAT dari Data Lalu Lintas Dengan Metode Inferensi-Bayes Menggunakan EMME”, Fakultas Teknik Program Studi Teknik Sipil Universitas Sebelas Maret. Surakarta.

Syafi'i.,2015, "Pendekatan Perencanaan Transportasi Perkotaan". https://www.coursehero.com/file/11166254/bab-2-pendekatan-perencanaan-transportasi-perkotaan1/. Diambil dari coursehero

Tamin, Ofyar Z., 2000, "Perencanaan dan Pemodelan Transportasi", Penerbit Institut Teknologi Bandung. Bandung. 